\title{
AvaliaÇÃo do Comportamento HidROGEOlógico dAS Formações Geológicas em uma Vertente da SerRa DO GANDARELA: RIO ACIMA, MG
}

e-Xactal

ISSN: 1984-3151

\author{
Evaluation Hydrogeological Behaviour of Geological \\ Formations on a StRand of SerRa do Gandarela: Rio Acima, \\ MG
}

\author{
Fernanda Bárbaro Franco ${ }^{1}$; Sidney Portilho²; Juliana Batista de Souza ${ }^{3}$
}

1 Graduada em Engenharia Ambiental. Centro Universitário de Belo Horizonte - UNI BH, 2015. Belo Horizonte, MG. fernanda.bfranco@yahoo.com.br.

2 Mestre em Geografia e análise ambiental. Universidade Federal de Minas Gerais, 2003. Professor do Centro Universitário de Belo Horizonte - UNI BH. Belo Horizonte, MG. sidneyportilho@yahoo.com.br.

3 Mestre em Biologia Vegetal. Universidade Federal de Minas Gerais, 2003. Professora do Centro Universitário de Belo Horizonte - UNI BH. Belo Horizonte, MG. juliana.souza@prof.unibh.br.

Recebido em: 18/03/2016 - Aprovado em: 15/05/2017 - Disponibilizado em: 31/05/2017

RESUMO: A Serra do Gandarela apresenta uma das maiores reservas hídricas do Quadrilátero Ferrífero e seus aquíferos são de extrema importância para as áreas de drenagens das bacias hidrográficas ali presentes. Possui grande grau de conservação, belezas naturais e uma grande biodiversidade. É uma região que abriga várias espécies vegetais endêmicas e a canga, afloramentos ferruginosos, que é um dos sistemas ecológicos mais ameaçado do Brasil. Esse artigo visa trabalhar a relação entre os solos, coberturas de superfície da Serra do Gandarela e o comportamento hidrológico dos mesmos, demonstrando a capacidade de campo, armazenamento de água, e as taxas de infiltração de água de cada ponto amostrado. Dos três pontos selecionados dois apresentaram bons resultados quanto à recarga hídrica. O primeiro ponto por apresentar um sistema lento de infiltração e percolação e o segundo ponto por infiltrar grande quantidade de água. O terceiro ponto apresentou uma taxa de infiltração menor, por possuir a textura da parte cimentante da matriz coluvionar (argilo - arenosa), o que interferiu negativamente no processo de infiltração. Relacionando todos os pontos com os respectivos resultados verifica-se que a Serra do Gandarela é uma região importante para o processo de recarga hídrica da região metropolitana de Belo Horizonte.

PALAVRAS-CHAVE: Serra do Gandarela. Canga. Infiltrômetro. Recarga Hídrica. Solos. Taxa de infiltração.

ABSTRACT: Serra do Gandarela presents one of the biggest hydric stock of the Ferriferous Quadrangle and its aquifers are of utmost importance for draining areas of these existing watersheds. It has a great conservation degree, natural beauties, a great biodiversity. It's a region wich shelters several vegetal endemic species and the "canga", ferruginous outcrops, which is one of the most endangered ecological systems in Brazil. This article aims to work the relationship between the soil surface, covers the Serra do Gandarela and the hydrological behavior of the same, demonstrating the field capacity, water storage, and water infiltration rates of each chozen location. Of the three selected points two showed good results as to water recharge. The first point by presenting a slow infiltration and percolation system and the second point for infiltrating large amount of water. The third point presented a lower infiltration rate by having the texture of the cementitious matrix of the colluvial (clayey 
- sandy) which negatively interfere with the infiltration process. Listing all the points with the results it appears that the Serra do Gandarela is an important region for the water refilling process of the metropolitan region of Belo Horizonte.

KEYWORDS: Serra do Gandarela. Canga. Infiltrometer. Recharge the aquifers. Soils. Infiltration rate.

\section{INTRODUÇÃo}

O Quadrilátero Ferrífero é conhecido como uma região de grande riqueza mineral e que durante séculos seus recursos têm sido explorados. Apesar dessa intensa extração mineral algumas áreas ainda continuam em condições ambientais conservadas ou com pouca atividade antrópica. Essa região se destaca no contexto nacional e internacional por sua grande produção mineral. Em meados do século XVII, iniciaram-se as atividades de exploração de minério. Começou com a extração do ouro e hoje abriga grandes minerações de ferro, ouro e alguns empreendimentos de mineração que exploram jazidas de outros tipos de rochas e minerais como, por exemplo, topázio e bauxita (MARENT; LAMOUNIER; GONTIJO, 2011).

Nessas áreas encontram-se belas paisagens e rica biodiversidade e é nesse contexto que a Serra do Gandarela ganha destaque, pois apresenta grande grau de conservação, belezas naturais, alta biodiversidade, riqueza paisagística, e inúmeras nascentes (LAMOUNIER; CARVALHO; SALGADO, 2011). A Figura 1 mostra a localização da Serra do Gandarela no Quadrilátero Ferrífero.

A associação entre a geologia bastante diversificada com o relevo parece exercer uma influência direta nas formações vegetais. Uma parte é representada por uma vegetação campestre muito diversificada (campo limpo, campo sujo e campo rupestre) e a maior parte corresponde à Floresta Estacional Semidecidual (Mata Atlântica). Nas porções mais elevadas do relevo, os campos rupestres podem ainda ser classificados com quartzíticos ou ferruginosos (MARENT; LAMOUNIER; GONTIJO, 2011).

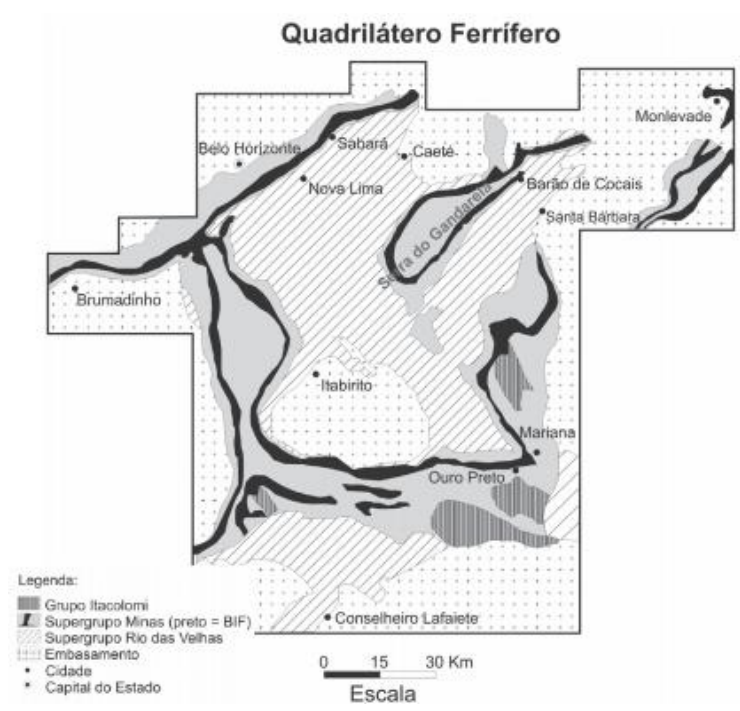

Figura 1 - Localização da Serra do Gandarela no Quadrilátero Ferrífero

Fonte - SILVA; SALGADO, 2009 - adaptado pelos autores.

De acordo com o ICMBio (2010), o Gandarela é um divisor das bacias hidrográficas do rio Doce (Piracicaba) e São Francisco (rio das Velhas) e ainda forma um corredor ecológico natural até o Caraça unindo as duas bacias. A área apresenta nascentes $\mathrm{e}$ cursos d'água enquadrados como Classe Especial e Classe 1. Segundo Lamounier, Carvalho e Salgado (2011) a região possui muitos córregos e nascentes, tornando-se importante patrimônio hídrico. Essa área apresenta uma das maiores reservas hídrica subterrâneas do Quadrilátero Ferrífero.

A Serra do Gandarela apresenta afloramentos ferruginosos, também conhecidos como cangas, que estão entre os sistemas ecológicos mais ameaçados 
do Brasil. As cangas abrigam várias espécies vegetais raras e endêmicas. As espécies estão distribuídas entre diversos ambientes e fitofisionomias, entre elas fitofisionomias florestais, arbustivas savânicas e campestres (CARMO, 2010).

Os diversos tipos de plantas podem absorver água por toda a superfície do solo, mas a maior parte do suprimento hídrico da planta vem das camadas mais profundas do solo. A água no solo é proveniente da chuva que se infiltra gradualmente até a altura do lençol freático. Uma parte da água infiltrada, a água capilar, é retida e estocada nos poros do solo (LARCHER, 2004).

Ainda não existem publicações expondo a relação da infiltração de água superficial e tipo de raízes em áreas de canga, mas sabe-se que as espécies herbáceas, arbustivas e arbóreas desenvolvem raízes que cobrem o solo diferentemente.

Caracteristicamente, as plantas herbáceas desenvolvem mais raízes finas e superficiais o que facilita a captação de água superficial mais rapidamente, e são plantas de menor porte. As plantas arbustivas já são de porte um pouco maior e por isso desenvolvem raízes mais profundas, mas podem desenvolver raízes superficiais, porém em menor concentração. As plantas arbóreas desenvolvem muito bem as raízes mais espessas e profundas, que tendem buscar água em horizontes do solo mais profundos. As raízes são mais espessas, pois precisam sustentar o maior porte do vegetal e, embora as espécies arbóreas possam desenvolver também raízes mais finas, estas, porém também são mais profundas. Logo as plantas herbáceas e arbustivas se beneficiam mais da água disponível na superfície de solos pouco drenados do que em solos mais drenados, onde por sua vez as plantas arbóreas se beneficiam mais.

$\mathrm{Na}$ Serra do Gandarela, repletas de espécies herbáceas e arbustivas, que se encontra uma das últimas áreas bem conservadas de Cangas do Estado de Minas Gerais. Por esse motivo deve-se ressaltar aqui que as cangas têm um papel importantíssimo na alimentação das nascentes, pois a água da precipitação cai sobre elas e escoa lentamente para o interior das rochas, formando os aquíferos que mantêm os rios mesmo na estação seca (ICMBio, 2010). Isso se deve provavelmente por auxílio da interação do solo com as plantas inseridas nessas cangas, porém para se ter esta certeza, é preciso desenvolvimento de pesquisas buscando fazer este paralelo.

De acordo com o ICMBio (2010), encontra-se no interior e nas vertentes da serra a maior e mais preservada Mata Atlântica de toda a região, sendo predominante a Floresta Estacional Semidecidual. Juntamente com os campos rupestres e os campos de altitude, guarda rica diversidade de flora e fauna.

A área de estudo situa-se na porção central de Minas Gerais, no contexto geoestrurural do chamado "Quadrilátero Ferrífero". O Quadrilátero Ferrífero situase no segmento meridional do Cráton do São Francisco que compõe uma entidade geotectônica neoproterozóica formada por rochas arqueanas e paleoproterozóicas pouco afetadas pelo evento tectonotermal Brasiliano. Nessa região são encontradas cinco grandes unidades litoestratigráficas pré-cambriana: 1) Embasamento arqueano; 2) Supergrupo Rio das velhas; 3) Supergrupo Minas; 4) Grupo itacolomi; 5) Rochas intrusivas pós-itacolomi (ALKMIM; MARSHAK, 1998 apud MOURÃO, 2007).

Segundo Marent e Salgado (2010), o Embasamento Cristalino, de idade arqueana, é composto por granitos, gnaisses e migmatitos.

O Supergrupo Rio das Velhas é composto por rochas do grupo Nova Lima - unidade basal do Supergrupo Rio das Velhas sendo constituído por filitos, filitos grafitosos, clorita-xistos, sericita-xistos, metagrauvacas, rochas máficas e ultramáficas, 
formações ferríferas tipo Álgoma, metacherts e matadolomitos - e Maquiné - é a unidade topo do Supergrupo Rio das Velhas, este grupo é composto pelas formações, da base para o topo: Palmital, constituída por quartzitos sericíticos, filitos quartzosos e filitos; e Casa forte, constituída por quartizitos sericíticos, cloríticos a xistosos e filitos (DORR, 1969).

O Supergrupo Minas, de idade paleoproterozóica, e composta basicamente por quartzitos e itabiritos. E por fim o Grupo Itacolomi, de idade proterozóica, composto basicamente por quartizitos (MARENT; SALGADO, 2010). A Figura 2 mostra a geologia do Quadrilátero Ferrífero.

Marent e Salgado (2010) citam que o Quadrilátero apresenta em linhas gerais o relevo dobrado em anticlinais e sinclinais, sendo que as anticlinais foram denudadas e agora ocupam a porção inferior do relevo, e as sinclinais, protegidas em suas abas por litotipos mais resistentes, permaneceram suspensas.

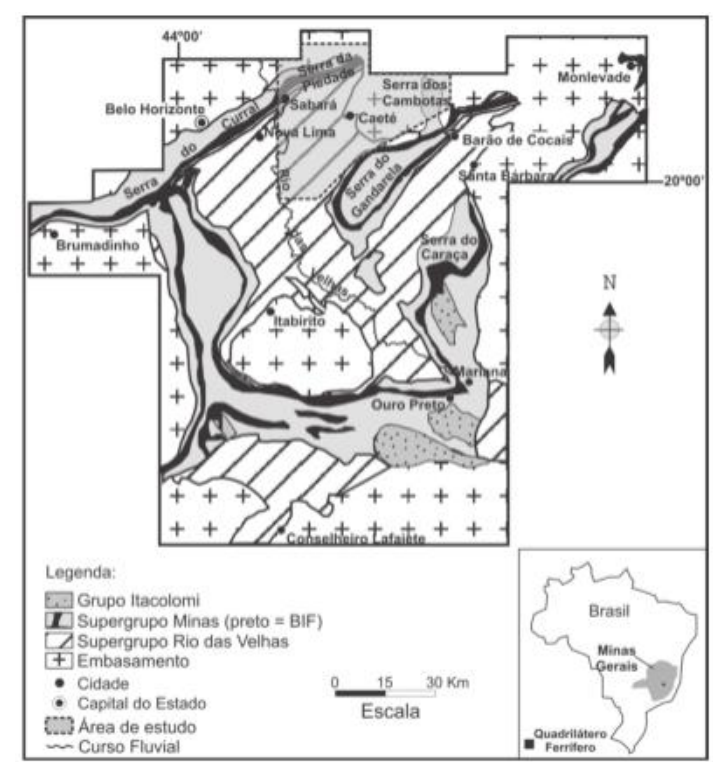

Figura 2 - Geologia do Quadrilátero Ferrífero Fonte - MARENT; SALGADO, 2010.

Diante do que foi descrito, este trabalho tem como foco demonstrar como o processo de infiltração e percolação da água, associada com as características ecossistêmicas do Gandarela interferem na paisagem e na recarga hídrica regional, realizando levantamentos detalhados do meio físico em uma vertente representativa da Serra do Gandarela e o diagnóstico de montante a jusante. Foram analisadas: A topografia, morfologia, cobertura pedológica, cobertura vegetal, tipologia da vegetação e comportamento hidrológico do solo. O objetivo deste artigo foi correlacionar os resultados encontrados dos levantamentos e verificar o comportamento hidrogeológico da região.

\section{Metodologia}

A realização deste trabalho e seus procedimentos metodológicos passaram pelas seguintes etapas: Levantamento bibliográfico, visitas técnicas no local de estudo e coleta de dados. O levantamento bibliográfico permitiu buscar trabalhos de relevância no Quadrilátero Ferrífero, sobretudo aqueles com enfoque na região.

Foram realizadas visitas técnicas no local para escolha da vertente mais representativa e para análise do local. A primeira visita foi realizada no dia 14 de setembro de 2014, com a finalidade de conhecer o local, a segunda visita foi no dia 26 de setembro de 2015, para a escolha da área de estudo (Figura 3).

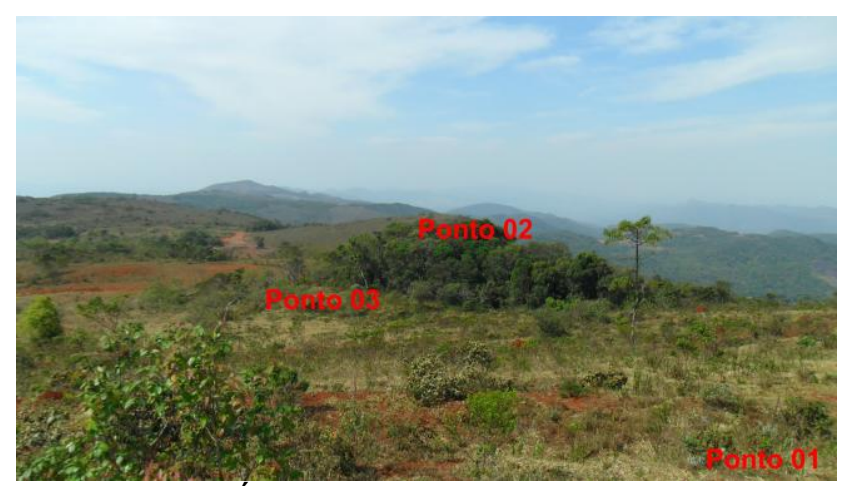

Figura 3 - Area escolhida para a realização do trabalho Fonte - Próprio autor. 
A vertente escolhida possui todas as características necessárias para o estudo, pois nela encontram-se três áreas distintas: A de canga, a de Mata Estacional Semidecidual e Campo ferruginoso (área de colúvio). O Ponto 01 , coordenadas geográficas $20^{\circ} 3^{\prime} 43.23^{\prime \prime} S$ 4341'39.02"O, é uma área de "canga couraçada" com pouca vegetação. $\mathrm{O}$ Ponto 02 , coordenadas geográficas $20^{\circ} 3^{\prime} 41.10^{\prime \prime} \mathrm{S} 43^{\circ} 41^{\prime} 37.42$ "O, é uma área de Mata Atlântica, tendo o solo coberto com serapilheira e com muitas raízes. O Ponto 03, coordenadas geográficas $20^{\circ} 3^{\prime} 39.41^{\prime \prime} \mathrm{S} 43^{\circ} 41^{\prime} 37.71^{\prime \prime} \mathrm{O}$, apresenta pouca vegetação com predominância de gramíneas.

A coleta de dados foi realizada no dia 13 de outubro de 2015. Foram coletados os dados com o infiltrômetro, clinômetro e também foram coletadas as amostras de solos.

O clinômetro foi utilizado para medir a inclinação do terreno. Primeiro posicionaram-se as estacas de 10 em $10 \mathrm{~m}$, iniciando do ponto mais alto para o ponto mais baixo. Depois com o clinômetro mediu-se 0 ângulo de inclinação. Após a coletada de dados calculou-se a inclinação da vertente. Selecionaram-se pontos considerados representativos na alta, média e baixa vertente para realização dos experimentos.

O infiltrômetro foi utilizado para calcular a taxa de infiltração de água no solo. Utilizou-se o infiltrômetro cilíndrico, pois é de fácil manuseio em comparação aos outros métodos, além de apresentar baixo custo. O tubo cilíndrico tem duas marcações, uma na altura de $5 \mathrm{~cm}$ e outra na altura de $10 \mathrm{~cm}$. A proveta do infiltrômetro é graduada em $\mathrm{mL}$ e tem uma torneira dosadora acoplada. Na realização das medições 0 cilindro foi introduzido $5 \mathrm{~cm}$ no solo (Figuras 4 e 5), com o auxílio de um martelo anti-repique, para evitar abalos na estrutura do solo.

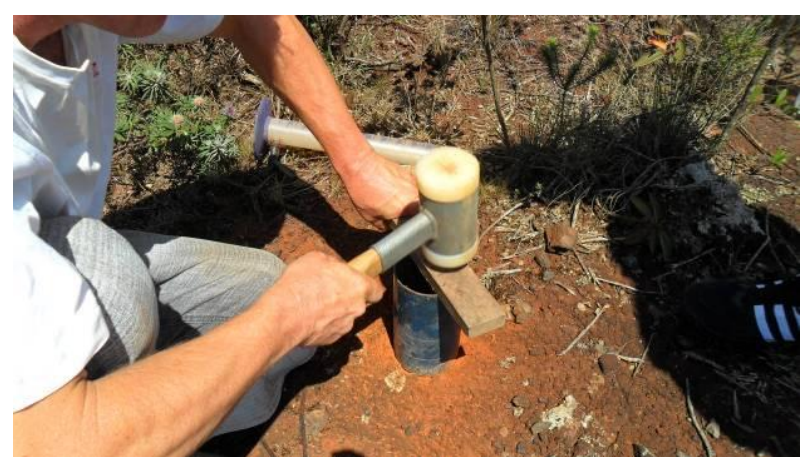

Figura 4 - Introdução do cilindro no terreno com o auxílio do martelo anti-repique, na área de canga, ponto 01

Fonte - Próprio autor.

Após a preparação do equipamento, realizou-se, de modo repetido, o procedimento. Encheu-se a proveta com água anotando-se a quantidade em $\mathrm{mL}$ e o tempo gasto para total infiltração da água no solo. Realizouse esse procedimento até estabilizar a infiltração.

Posteriormente a coleta dos dados em campo, foram analisados e discutidos os resultados, os quais serão demonstrados no decorrer desse trabalho.

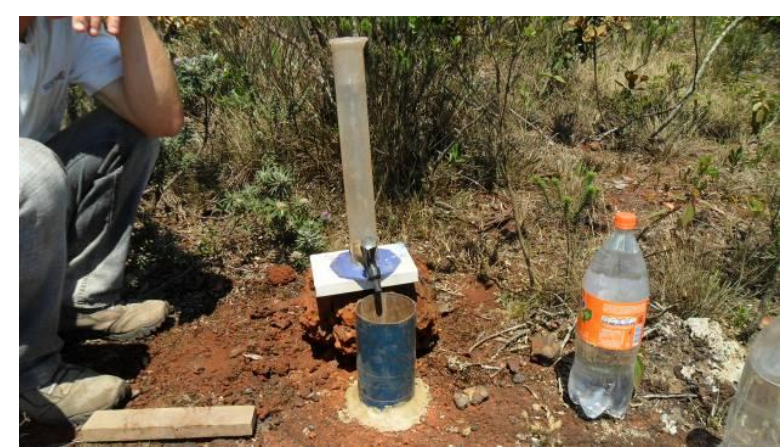

Figura 5 - Infiltrômetro pronto para a realização do experimento na área de canga, ponto 01 Fonte - Próprio autor.

Para a análise das raízes no solo utilizou-se o Manual de Descrição e Coleta de Solo no Campo (SANTOS et al., 2013). Em laboratório foram analisadas as amostras de solos coletadas em campo e mediu-se o tamanho e o diâmetro das raízes com o uso de uma régua de $30 \mathrm{~cm}$. Posteriormente, com o uso do Manual, verificou-se a sua classificação.

Para a apreciação da cor do solo foi utilizada a tabela Munsell (2000) e para a estrutura e textura foram feitos os testes de campo. 


\subsection{Caracterização da Área de Estudo}

\subsubsection{Serra do Gandarela}

O sinclinal Gandarela está localizado na porção norte do Quadrilátero Ferrífero e é formado por metassedimentos do Supergrupo Minas em contato com o Grupo Nova Lima, pertencente ao Supergrupo Rio das Velhas e o embasamento composto por rochas graníticas do Complexo Metamórfico Caeté. Atualmente considerado como uma região com grandes perspectivas para prospecção de minério de ferro (OLIVEIRA; ENDO; OLIVEIRA, 2005).

Em relação à vegetação, a região da Serra do Gandarela apresenta um mosaico de formações vegetais. Essa diversidade de fitofisionomias ocorre em virtude de ser uma área de transição entre os Biomas Mata Atlântica e Cerrado. Encontram-se na região campos rupestres, tanto ferruginoso quanto quartizíticos; campo limpo e campo sujo e a Floresta Estacional Semidecidual. A Sinclinal Gandarela apresenta também a canga, que constitui áreas de alto valor para conservação, devido a seus importantes atributos, como a raridade e endemismo de plantas (LAMOUNIER; CARVALHO; SALGADO, 2011).

A Serra do Gandarela está localizada a sudeste da capital mineira, na Área de Proteção Ambiental Sul da Região Metropolitana de Belo Horizonte. Situa-se entre a Serra do Caraça e a Serra da Piedade, como mostra a Figura 6. Abrange os municípios de Barão de Cocais, Caeté, Santa Bárbara, Rio Acima, Raposos e Itabirito (ICMbio, 2010).

Formando um corredor ecológico com o Caraça, o Gandarela é uma das últimas áreas ainda bem preservadas de toda a região com significativa extensão de Mata Atlântica e campos rupestres sobre cangas (ICMBio, 2010).

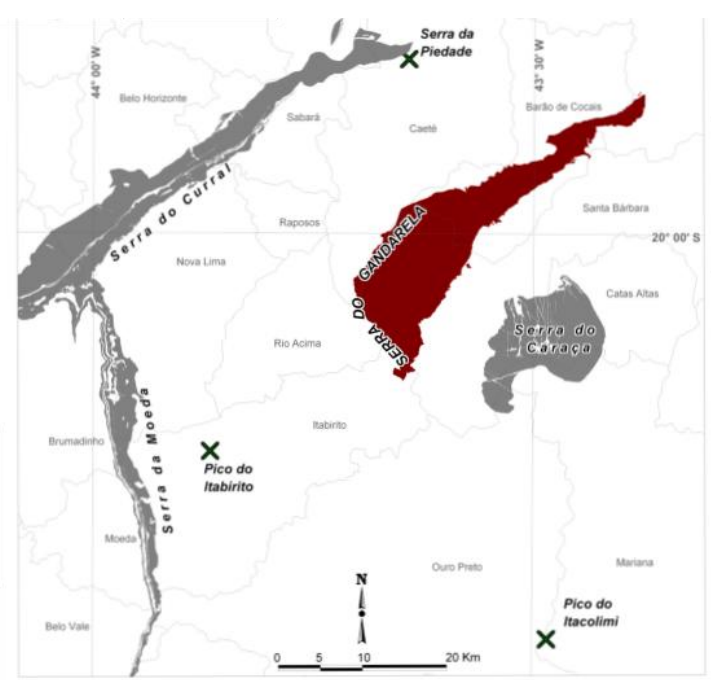

Figura 6 - Localização Serra do Gandarela Fonte - PROJETO MANUELZÃO, 2010.

\subsubsection{CANGA}

A canga apresenta espessura variável de 2 a $10 \mathrm{~m}$, constituindo de fragmentos de formação ferrífera, hematita compacta e minoritariamente outros minerais, cimentados por óxidos de ferro hidratado (MOURÃO, 2007).

Ainda de acordo com Mourão (2007), as cangas podem ser sobrepostas por solo altamente poroso com fragmentos ferruginosos e demais sedimentos terciários e quaternários como lateritas e mudstone. $\mathrm{O}$ autor Dorr (1969) apud Mourão (2007) classifica as cangas em três tipos:

1) Canga rica - é uma brecha ou conglomerado de
hematita compactada por pouca limonita, com teor
de ferro superior a $66 \%$. O cimento preenche total
ou parcialmente os interstícios dos grãos, no
entanto, a maior parte dos poros encontra-se vazia;
2) Canga comum - é constituída por lascas de
hematita e fragmentos de itabirito em proporção de
20 a $80 \%$ da rocha, cimentados por limonita; e
3) Canga química - consiste, principalmente, de
limonita cimentando argila e solo ferruginoso. Exibe
baixa porosidade e permeabilidade (DORR, 1969
apud MOURÃO, 2007, página 32).

A canga tem a sua origem associada ao ferro dissolvido no processo de intemperismo e depositado pela evaporação da água subterrânea, durante as estações secas, que cimentou os detritos provenientes 
da desagregação das rochas da Formação Cauê (DORR, 1969 apud MOURÃO, 2007).

Os solos do Quadrilátero são considerados endêmicos por refletirem a diversidade geoambiental das áreas ferríferos, pois seus solos são desenvolvidos sobre as cangas (SCHAEFER et al., 2008 apud CARMO, 2010).

Segundo Carmo (2010) pode-se considerar que as cangas compõem um sistema geoecológico metalífero, recobrindo insularmente uma matriz geológica predominantemente constituída por litotipos também ricos em ferro.

\section{Análise dos Elementos da Serra do}

\section{GANDARELA}

\subsection{Topografia e Morfologia}

Segundo Marent (2013) a região do Gandarela apresenta uma morfologia em formas de cristas, escarpas, morros e colinas. Esse autor ainda afirma que a litoestrutura desempenha grande domínio na configuração da paisagem através da erosão diferencial e do sistema de falhas e fraturas, o que proporciona mais suscetibilidade de áreas à desnudação, influenciando o modelado movimentado do relevo que se distribui em diferentes unidades de paisagem. $\mathrm{O}$ autor ainda afirma que devido à essa variedade litológica e declividade, da região, as escarpas da borda sinclinal apresentam em algumas porções uma topossequência truncada, com polaridade evolutiva crescente do topo para a base.

\subsection{Cobertura Pedológica}

A Embrapa (2014) classifica o solo como:

Uma coleção de corpos naturais, constituídos por partes sólidas, líquidas e gasosas, tridimensionais, dinâmicos, formados por materiais minerais e orgânicos, contendo matéria viva e ocupando a maior porção do manto superficial das extensões continentais do planeta. Contém matéria viva e pode ser vegetado na natureza onde ocorrem e, eventualmente, modificados por interferências antrópicas (EMBRAPA, 2014, página 14).

Segundo Shinzato e Carvalho Filho (2005) apud Marent (2013) os solos que predominam na região da Serra do Gandarela são os Neossolos e Cambissolos, muito associados a um relevo forte ondulado a montanhoso. Esses solos associados ao material de origem e a topografia geram uma variedade de formações vegetais.

\subsection{Cobertura Vegetal e Tipologia da VEGETAÇÃo}

A Serra do Gandarela, em termos de vegetação, apresenta um mosaico de formações vegetais. Tal diversidade de fitofisionomias se dá pelo fato de ser uma área de transição entre os Biomas Mata Atlântica e Cerrado (LAMOUNIER; CARVALHO; SALGADO, 2011).

A ICMbio (2010), destaca que essa região contém importantes remanescentes de Mata Atlântica semidecídua, de vegetação de campos rupestres sobre canga e sobre quartzito, em transição com formações do Cerrado. As Figuras de 7 a 9 mostram a heterogeneidade ambiental e as diversas fisionomias vegetais encontradas em cangas.

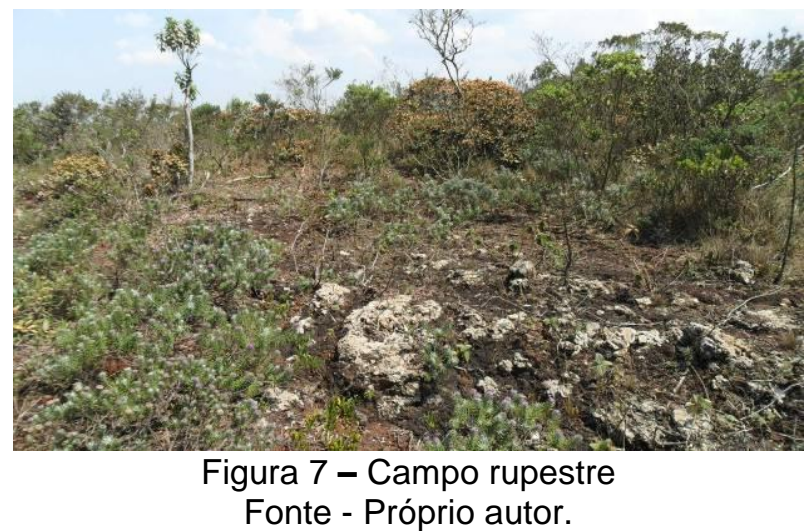

e-xacta, Belo Horizonte, v. 10, n. 1, p. 1-15. (2017). Editora UniBH doi: 10.18674/exacta.v10i1.1780 
Segundo Mendonça e Lins (2000) apud Lamounier, Carvalho e Salgado (2011), nos campos rupestres além de terem presença de espécies de ocorrência restrita, essa vegetação possui grande valor paisagístico, elevada biodiversidade e suas plantas possuem uma riqueza de adaptações morfológicas e fisiológicas que Ihes conferem possibilidades de sobreviver às condições extremas de temperatura, de solos com grande lixiviação e baixa disponibilidade de água no solo.

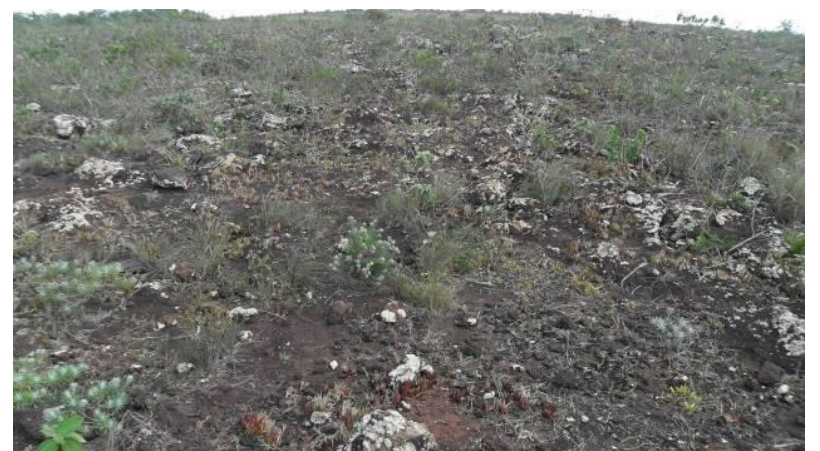

Figura 8 - Campo ferrruginoso nas proximidades do ponto 01 de amostragem Fonte - Próprio autor.

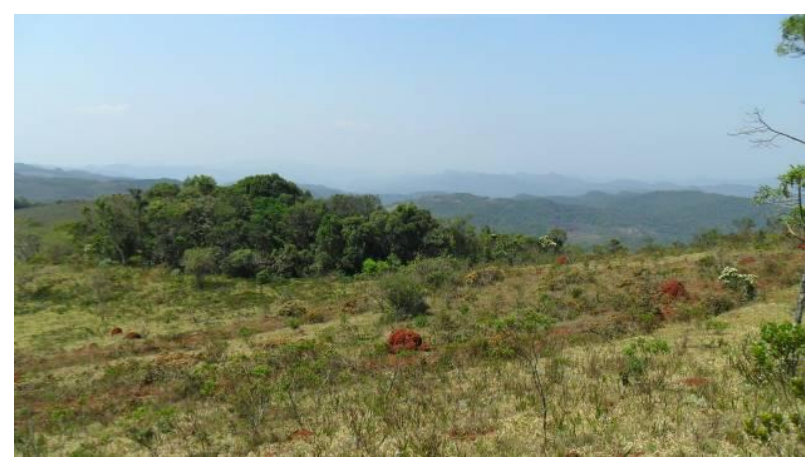

Figura 9 - Campo ferruginoso com mancha de Floretas Estacional Semidecídua (ponto 03 de amostragem)

Fonte - Próprio autor.

A ICMBio (2010) ressalta que várias espécies presentes nessa região desenvolveram adaptações altamente específicas para a sua sobrevivência em solo com elevado teor de metais. As chamadas "metalófitas" são plantas conhecidas como portadoras de adaptações que levam ao aumento das concentrações de metais em seus tecidos. Essas plantas são encontradas nas cangas, e apresentam alta taxa de endemismo, na medida em que estas se tornam espécies incapazes de sobreviver em solos que não tenham as altas taxas de concentrações de metais.

De uma maneira geral, segundo Salgado (2006) a vegetação do Quadrilátero Ferrífero, acompanha o relevo, predominando os campos de altitude nas terras altas e as savanas (cerrado) e florestas semideciduas nas terras baixas.

\section{Resultados e Discussão}

O presente trabalho realizou amostragens em três locais diferentes na Serra do Gandarela (Figura 10).

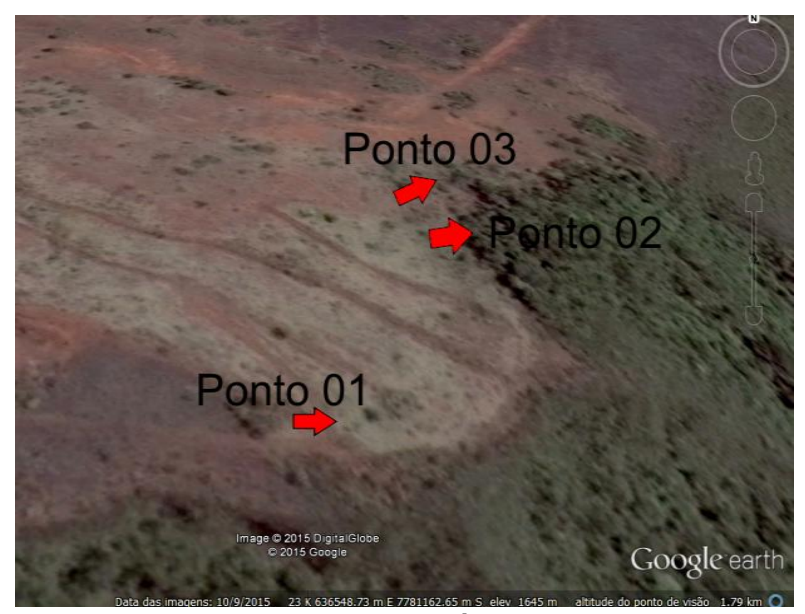

Figura 10 - Vista parcial da área estudada, com a marcação dos três pontos estudados

Fonte - GOOGLE - adaptado pelos autores.

\subsection{Cobertura Pedológica}

Ponto 01 , verificou-se que a cobertura pedológica era uma crosta laterítica. Essas crostas são altamente coesas e apresentam baixa erodibilidade.

Ponto 02, identificou-se como uma zona de Cambissolo. O Cambissolo é um solo pouco desenvolvido, com horizonte B incipiente, apresentando, em geral, fragmentos de rochas permeando a massa do solo e/ou minerais primário, fraco desenvolvimento de estrutura e cor (EMBRAPA, 2014). 
Ponto 03, identificou-se como uma rampa de colúvio. Segundo Santos e Vidal, 2003, os colúvios são deposições terrosas ou de detritos rochosos que se acumulam em vertentes ou sopés de encostas mais ou menos acentuadas, transportados principalmente pela ação da gravidade.

\subsection{Perfil Topográfico}

Utilizando o Clinômetro obtiveram-se os dados que demonstram a declividade da área estudada (Figura 11).

Começou a coleta de dados no ponto da área de canga, ponto 01 , onde se tem a maior altitude. Foram coletados os dados da inclinação de $10 \mathrm{em} 10 \mathrm{~m}$ até o último ponto estudado.

Após a coleta de dados e a realização dos cálculos observou-se que a topografia da área estudada apresenta uma vertente com declividade suave. Os pontos amostrados representam nuances semelhantes de inclinação.

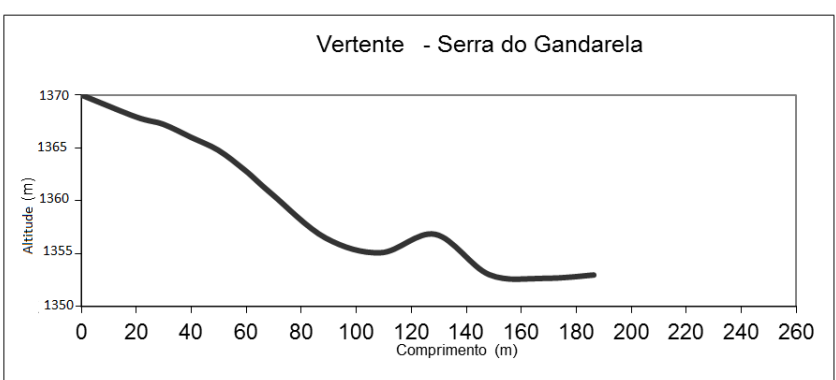

Figura 11 - Vertente da área estudada Fonte - Próprio autor.

\subsection{Infiltração e Percolação da Água nas Formações Geológicas/Pedológicas SUPERFICIAIS}

Através do uso do infiltrômetro foi possível analisar a taxa de infiltração em três pontos distintos na Serra do Gandarela. O ponto 01 foi na área de canga. Nesse ponto a taxa de infiltração foi muito baixa, quase não houve infiltração. Esse fato é explicado por se tratar de uma "canga couraçada", com baixa permeabilidade. Após a retirada do cilindro parte da água escorreu e parte continuou empossada como mostra a Figura 12. A taxa de infiltração nesse ponto foi quase nula, como mostra a Figura 13. Em 16 minutos infiltraram-se somente $25 \mathrm{~mL}$.

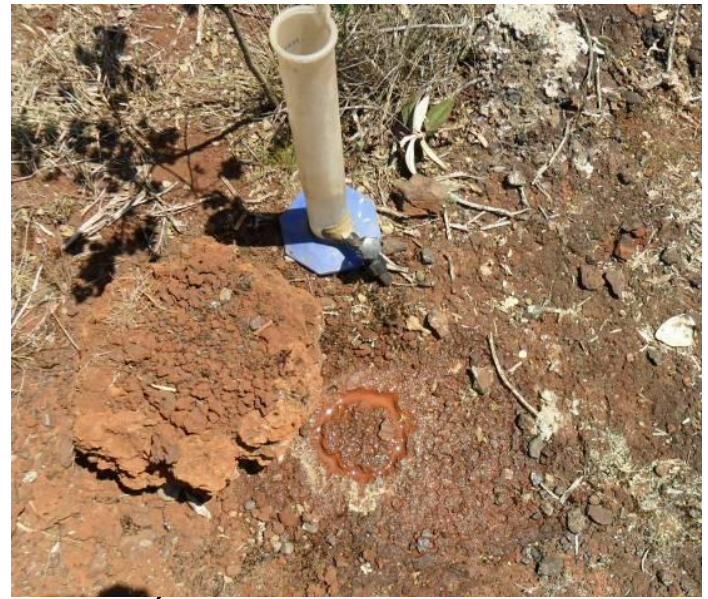

Figura 12 - Água empossada depois da retirada do cilindro do infiltrômetro Fonte - Próprio autor.

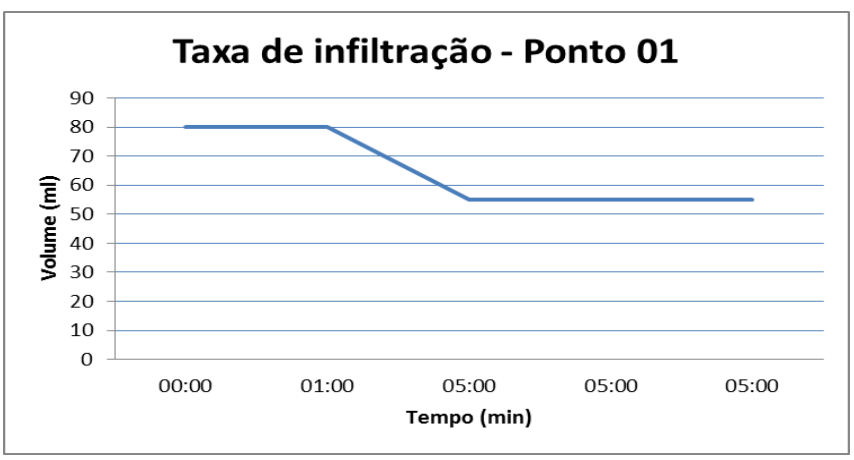

Figura 13 - Valores referentes à taxa de infiltração em $\mathrm{mL}$ do ponto 01

Fonte - Próprio autor.

A canga tem uma característica importante, pois em alguns tipos de canga a capacidade de armazenar água é muito boa. Entretanto, ficou claro pelo experimento de infiltração em campo que a entrada de água nesse sistema se dá por fraturas superficiais e não na textura granular da mesma. Essa conclusão se deve à baixa capacidade de infiltração diagnosticada no corpo principal da couraça.

e-xacta, Belo Horizonte, v. 10, n. 1, p. 1-15. (2017). Editora UniBH doi: 10.18674/exacta.v10i1.1780 
O ponto 02 analisado se localiza dentro de uma mata fechada. O solo estava coberto de serapilheira e tinha muitas raízes finas e superficiais. Preparou-se o local com a retirada da serapilheira e montagem do equipamento. A medição foi realizada durante $17 \mathrm{~min}$ e $36 \mathrm{~s}$, nos primeiros nove minutos houve um aumento na taxa de infiltração. Os primeiros $1000 \mathrm{~mL}$ estavam infiltrando em um tempo médio de três minutos, após os $2000 \mathrm{~mL}$ o tempo reduziu e se estabilizou em dois minutos e trinta e sete segundos, conforme mostra a Tabela 1.

Tabela 1

Medição feita em campo do tempo gasto para $500 \mathrm{~mL}$ de água infiltrar no solo (ponto 02)

\begin{tabular}{c|c}
\hline $\begin{array}{c}\text { Tempo (minutos e } \\
\text { segundos) }\end{array}$ & Volume $(\mathrm{ml})$ \\
\hline $03: 20$ & 500 \\
$03: 05$ & 500 \\
$02: 57$ & 500 \\
$02: 37$ & 500 \\
$02: 37$ & 500 \\
$02: 37$ & 500 \\
\hline
\end{tabular}

Fonte - Próprio autor.

A alta taxa de infiltração desse ponto pode ser explicada por ser um solo bem aerado por causa da grande quantidade de raízes presentes no solo e por se tratar de um Cambissolo (sequência de perfil apresentando horizonte A sucedido de B incipiente) com textura arenosa.

A Figura 14 mostra os valores do tempo e do volume infiltrado.

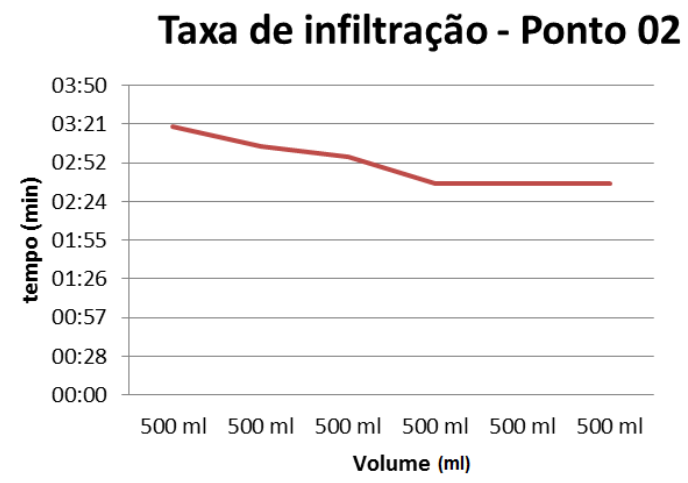

Figura 14 - Valores referentes à taxa de infiltração em $\mathrm{mL}$ do ponto 02

Fonte - Próprio autor.

O ponto 03 é uma área de colúvio. Apresenta pouca vegetação no local, com predominância de gramíneas. A medição foi realizada durante $36 \min$ e $40 \mathrm{~s}$ da medição, somente nos primeiros nove minutos houve uma diminuição na taxa de infiltração. A cada $500 \mathrm{~mL}$ de água adicionada no infiltrômetro a taxa de infiltração diminuiu, entretanto de forma mais gradual quando comparado com o ponto 02 do experimento. Esse resultado pode ser explicado pela estrutura e textura do solo/formação coluvionar. A composição de cobertura de superfície apresenta uma estrutura fraca, mas presente, o que favorece a infiltração intra estrutural (entre os poucos agregados de solo), por esse motivo nos primeiros minutos ocorreu uma boa infiltração. Entretanto, a textura argilo arenosa da parte cimentante da matriz coluvionar, interferiu negativamente no processo de infiltração seguinte, pois a argila pode agir selando a porosidade textural e porosidade intra estrutural, o que de fato ocorreu nesse ponto, diminuindo assim a taxa de infiltração com o passar do tempo.

A Tabela 2 mostra a medição realizada em campo do ponto três. Mostra o tempo gasto para $500 \mathrm{~mL}$ de água infiltrar no solo. 
Tabela 2

Medição feita em campo do tempo gasto para $500 \mathrm{~mL}$ de água infiltrar no solo (ponto 03)

\begin{tabular}{c|c}
$\begin{array}{c}\text { Tempo (minutos e } \\
\text { segundos) }\end{array}$ & Volume $(\mathrm{ml})$ \\
\hline $03: 22$ & 500 \\
$06: 15$ & 500 \\
$07: 50$ & 500 \\
$09: 25$ & 500 \\
$09: 48$ & 500 \\
\hline
\end{tabular}

Fonte - Próprio autor.

A Figura 15 mostra os valores do tempo e do volume infiltrado, na medição do ponto 03.

\section{Taxa de infiltração - Ponto 03}

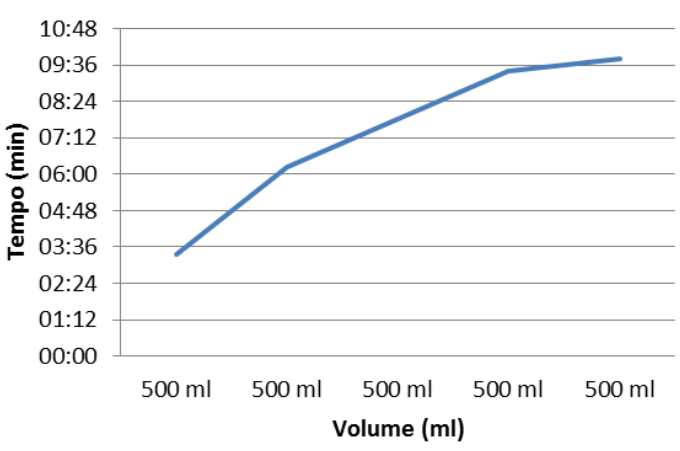

Figura 15 - Valores referentes à taxa de infiltração em $\mathrm{mL}$ do ponto 03

Fonte - Próprio autor.

Um fator importante nessa análise feita da taxa de infiltração é a quantidade de água que permanece no solo. Após uma chuva, a quantidade de água que permanece no solo, estocada nos poros, é chamada de água capilar e a parte que percola, de água gravitacional. A quantidade que irá permanecer como capilar ou como gravitacional depende, sobretudo, do tipo de solo e da distribuição do tamanho dos poros no mesmo (LARCHER, 2004).

Depois de saturado com água, e após toda a água gravitacional percolar, o solo será representado pela capacidade de campo, ou seja, capacidade de armazenamento de água no solo. Os solos com textura fina ou aqueles com grande quantidade de coloides ou matéria orgânica armazenam mais água do que solos de textura grossa, portanto a capacidade aumenta na seguinte sequência: areia, silte, argila e solo orgânico (LARCHER, 2004).

Nas amostras de solos recolhidas em campo, verificou-se que em regiões de mata densa (ponto 02 do experimento) a textura/granulometria encontrada, através de teste de campo, foi arenosa. Nessa região a capacidade de campo é baixa, ou seja, não conseguem armazenar muita água. Também foi encontrada textura argilo arenosa nas rampas de colúvio, apresentando uma capacidade de campo moderada.

\subsection{ANÁLISE dos Solos}

Ponto 01 analisado foi o de crosta laterítica. Quase não houve infiltração. A Figura 16 mostra a cobertura estudada.

Ponto 02 analisado foi no interior da Mata Estacional Semidecídua. O Solo desse ponto é o Cambissolo.

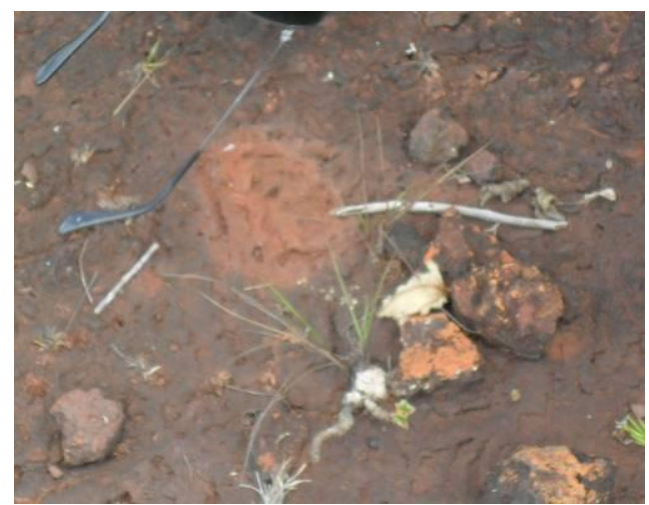

Figura 16 - Cobertura pedológica do ponto 01 , crosta laterítica

Fonte - Próprio autor.

O horizonte $A$ apresentou resquícios de fragmentos de canga de aproximadamente $5 \mathrm{~mm}$. A cor medida na tabela Munsell (2000) foi a 7.5yr3/1, cinza escuro. O tipo de estrutura é granular pequena com grau de estrutura moderado (Figura 17). Verificou-se através 
de teste de campo que a textura é predominantemente arenosa (areia grossa) com $60 \%$ de areia. Nesse ponto a infiltração é facilitada por dois fatores importantes: O primeiro fator são os agregados relativamente estáveis ocorrendo a infiltração intra agregados, o segundo é a porosidade textural ou porosidade primária.

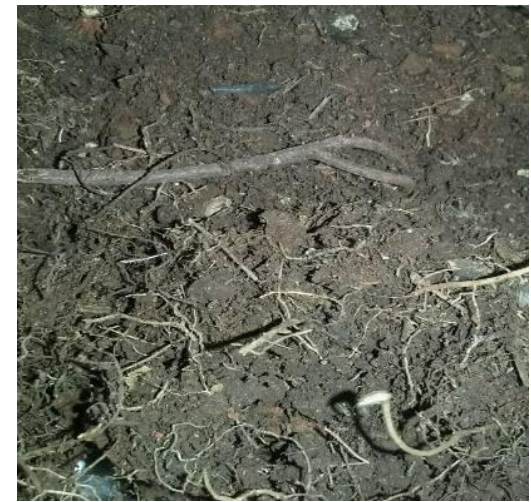

Figura 17 - Estrutura do Cambissolo, amostra do ponto 02

Fonte - Próprio autor.

Nessa amostra, 37\% da massa constituída do solo apresentou raízes (Figura 18). As raízes tinham o diâmetro de $1 \mathrm{~mm}$, Santos et al. (2013) classifica como finas $(1<\phi 2 \mathrm{~mm})$. Essa presença de raízes gera a porosidade secundária, o que facilita a infiltração de água no solo.

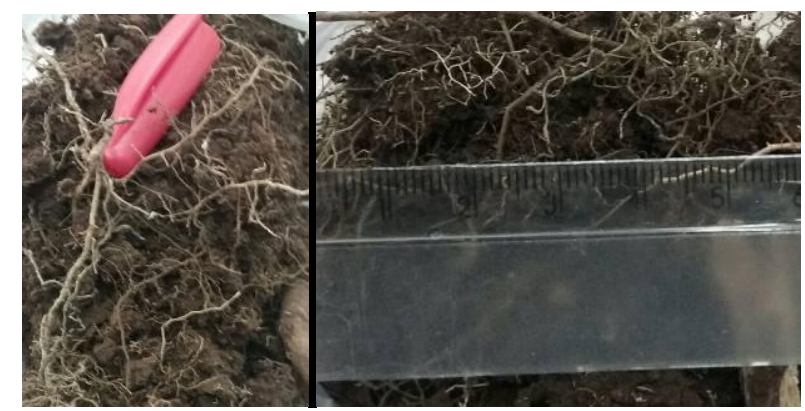

Figura 18 - Raízes presentes na amostra de solo do ponto 02

Fonte - Próprio autor.

Ponto 03 analisado, em uma área de campo ferruginoso, a cobertura pedológica encontrada foi a de uma rampa de colúvio. Verificaram-se na amostra características estruturais diversas, com pequenos fragmentos de canga.
Foram analisadas as duas cores predominantes da amostra do solo. A primeira cor, a cor dominante, medida na tabela Munsell (2000), foi a 2.5yr3/6 vermelho escuro. A segunda cor medida na tabela foi a $2.5 \mathrm{yr} 5 / 8$, vermelho.

Apesar de se tratar de rampa de colúvio, pela mistura de materiais (Figura 19), a parte superficial e a matriz de textura fina do colúvio já apresentam vestígios de organização pedológica. A estrutura incipiente na rampa é do tipo bloco sub angular médio que se desfaz em angular médio, nos primeiros $10 \mathrm{~cm}$. Analisando do ponto de vista da infiltração, a intra estrutura/fragmentos de canga apresentam grande potencial de infiltração. A textura da parte cimentante da matriz coluvionar é argilo arenosa. Baseado na coloração amostrada pode-se afirmar que as argilas cimentantes possuem grande percentual de óxido de ferro (hematita). Conclui-se, portanto, que a fração argila interfere negativamente na infiltração da água no solo, podendo selar a porosidade textural e porosidade intra estrutural.

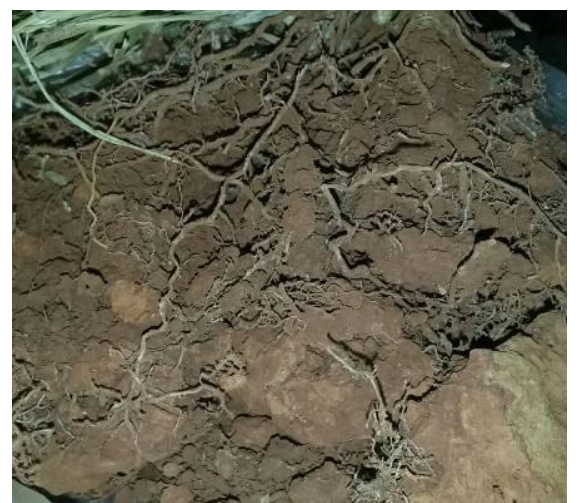

Figura 19 - Amostra do solo do ponto 03 , presença de mistura de materiais e pequenos fragmentos de canga Fonte - Próprio autor.

Nessa amostra, 23\% da massa constituída do solo apresentou raízes, com predominância de raízes com diâmetro de 2 mm (Figura 20). Santos et al. (2013) classifica como médias $(2<\phi 5 \mathrm{~mm})$. 


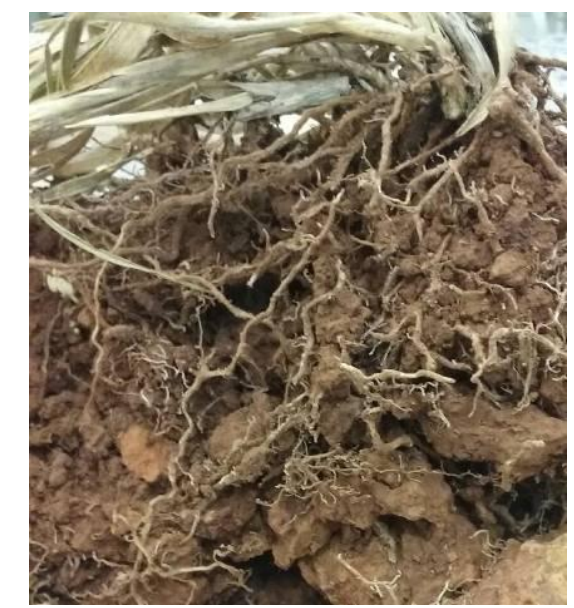

Figura 20 - Raízes com mais de $2 \mathrm{~mm}$ Fonte - Próprio autor.

\section{Conclusão}

Os solos dessa região apresentam características importantes quando se trata de infiltração da água no solo e recarga hídrica.

A canga pode apresentar boa capacidade de armazenamento de água, pois o processo de infiltração e percolação é lento, mas o retorno da água por exfiltração também tem a mesma característica. Como há infiltração mais acelerada em sistemas fraturados essa lenta exfiltração favorece a recarga hídrica dos lençóis freáticos, pois apresentará água no sistema por muito mais tempo, abastecendo os lençóis mesmo em época de seca.

No ponto 02 , a capacidade de armazenamento não é tão alta quanto o da canga, mas pela presença de grande quantidade de raízes a infiltração é facilitada o que também ajuda na recarga hídrica, pois o solo vai conseguir infiltrar grande quantidade de água.

Comparados os resultados obtidos nesse artigo com outros dois estudos realizados em Minas Gerais que utilizaram o mesmo método de estudo da taxa de infiltração, a Serra do Gandarela apresenta altos valores de infiltração de água no solo.

Considerando os dados de Portilho e Miranda (2008), os volumes infiltrados em experimentos na sub-bacia do Rio Piracicaba foram menores que na Serra do
Gandarela. Esse resultado pode ser explicado pelo fato da área estudada por Portilho e Miranda (2008) apresentar déficit de vegetação, o solo ser compactado por pisoteio do gado, pela erosão splash e pelas características do solo, que é mais evoluído Latossolo.

Analisando os dados de Portilho e Gregório (2011), a taxa de infiltração também é menor que a encontrada na Serra do Gandarela. A área estudada por foi em um Latossolo vermelho amarelo, a vegetação predominante é pastagem e algumas áreas estudadas já apresentavam solos compactados.

Percebe-se ao comparar esses artigos que a Serra do Gandarela por apresentar pouca intervenção antrópica e solos que favorecem a infiltração de água, desempenha um papel importante na recarga hídrica da região.

Confrontando os três artigos, em relação à taxa de infiltração, compararam-se a média de tempo com a média de água infiltrada e depois se calculou a proporção dessa taxa para cada área. Verificou-se que a taxa de infiltração na Serra do Gandarela é $51,4 \%$ maior que na encosta da Microbacia do Ribeirão Gomes de Melo em Piracicaba - MG e 91,8\% maior comparado às áreas estudadas em Itabira - MG. Conclui-se, portanto que por apresentar essas características essa área deve ser preservada e mais estudada a fim de se conhecer mais sobre essa região.

\section{Agradecimentos}

Agradeço ao meu orientador e a minha coorientadora, professores, colegas, amigos e familiares por todo apoio e orientações que contribuíram muito para a elaboração e enriquecimento desse artigo. 


\section{REFERÊNCIAS}

ALKMIM, F.F.; MARSHAK, S. Transamazonian Orogeny in the Southern São Francisco Craton Region, Minas Gerais, Brazil: evidence for Paleoproterozoic collision and collapse in the Quadrilátero Ferrífero. Precambrian Research, v. 90, p.29-58, 1998. apud MOURÃO, M. A. A.. Caracterização hidrogeologia do aquífero Cauê, Quadrilátero Ferrífero, MG [manuscrito]. 2007. 297 f. Tese (doutorado) - Escola de Engenharia, Universidade Federal de Minas Gerais, Belo Horizonte, 2007.

CARMO, F. F. Importância Ambiental e Estado de Conservação dos Ecossistemas de Cangas no Quadrilátero Ferrífero e Proposta de Áreas-Alvo para a Investigação e Proteção da Biodiversidade em Minas Gerais. 2010. 90f. Dissertação (Mestrado em Ecologia, Conservação e Manejo da Vida Silvestre) - Universidade Federal de Minas Gerais, Belo Horizonte, 2010. Disponível em:< http://www.icb.ufmg.br/pgecologia/dissertacoes/D240_ flavio_foneca_do_carmo.pdf>. Acesso em: 07 set. 2014.

DORR J. V. N.. Physiographic stratigraphic and structural development of the Quadrilátero Ferrífero, Minas Gerais, Brazil. Washington, DNPM/USGS, 1969, 110p. (Prof. Paper 641-A). Disponível em:<

https://pubs.usgs.gov/pp/0641a/report.pdf>. Acesso em: 09 de Abr. de 2017.

\section{EMBRAPA. Solos para todos - Perguntas e}

Respostas, 2014. Organizadores: Moema de Almeida Batista, Denise Werneck de Paiva, Alexandre Marcolino. - Dados eletrônicos. - Rio de Janeiro: Embrapa Solos, 2014. Disponível em:<http://ainfo.cnptia.embrapa.br/digital/bitstream/ite m/122505/1/Doc-169-Perguntas-e-Respostas.pdf>. Acesso em: 05 nov. 2015. ISSN 1517-2627. EMBRAPA - CENTRO DE PESQUISA AGROPECUÁRIA DOS CERRADOS. Cerrado: ambiente e flora. Planaltina - DF, 556p, 1998. apud LAMOUNIER, W. L. et al.. A influência da litologia na distribuição da cobertura vegetal e no uso do solo na Serra do Gandarela, Quadrilátero Ferrífero - MG. 2010. GEOgrafias Artigos Científicos.

Disponível em:

<http://cantacantos.com.br/revista/index.php/geografia s/article/view/109/107>. Acesso em: 19 set. 2015. ISSN 2237-549X.
ICMBio. Proposta De Criação Do Parque Nacional Da Serra Do Gandarela. 2010. Estudos Técnicos para a Criação de Unidade de Conservação Federal. Disponível em:

<http://www.icmbio.gov.br/portal/images/stories/o-quefazemos/PARQUE_GANDARELA_proposta_ICMBio.p df>. Acesso em: 30 out. 2015.

LAMOUNIER, W. L.; CARVALHO, V. L. M.; SALGADO, A. A. R.. Serra do Gandarela: Possibilidades de Ampliação das Unidades de Conservação no Quadrilátero Ferrífero - MG. 2011. Revista do Departamento de Geografia - USP, volume 22, p.171-192. Disponível em:

<http://www.revistas.usp.br/rdg/article/viewFile/47225/ 50961 >. Acesso em: 07 Set. 2014.

LARCHER, W. Ecofisiologia Vegetal. Editora RiMa, 2004.

MARENT, B. R.; SALGADO, A. A. R.. Mapeamento das unidades do relevo da porção nordeste do Quadrilátero Ferrífero - MG. 2010. GEOgrafias Artigos Científicos. Disponível em: <http://www.cantacantos.com.br/revista/index.php/geo grafias/article/view/107/105>. Acesso em: 17 out. 2014. ISSN 2237-549X.

MARENT, B. R.; LAMOUNIER, W. L.; GONTIJO, B. M.. Conflitos Ambientais na Serra do Gandarela, Quadrilátero Ferrífero - MG: mineração X preservação. 2011. GEOgrafias Artigos científicos. Disponível em:

$<$ http://cantacantos.com.br/revista/index.php/geografia s/article/view/133/131 >. Acesso em: 07 Set. 2014. ISSN 2237-549X.

MARENT, B. R.. Unidades De Paisagem Nas Bacias Hidrográficas Do Alto Ribeirão Da Prata E Ribeirão Preto Na Serra Do Gandarela, Quadrilátero Ferrífero - MG. 2013. 19 Folhas. Monografia - Centro Universitário de Belo Horizonte, Centro Universitário de Belo Horizonte, Belo Horizonte, 2013.

MENDONÇA, M. P.; LINS, L. V. (Orgs.). Lista Vermelha das Espécies Ameaçadas de Extinção da Flora de Minas Gerais. Belo Horizonte: Fundação Biodiversitas/ Fundação Zoo-Botânica de Belo Horizonte. 2000. 47 p. apud LAMOUNIER, W. L.; CARVALHO, V. L. M.; SALGADO, A. A. R.. Serra do Gandarela: Possibilidades de Ampliação das Unidades de Conservação no Quadrilátero Ferrífero - MG. 2011. Revista do Departamento de Geografia - USP, volume 22, p.171-192. Disponível 
em:

<http://www.revistas.usp.br/rdg/article/viewFile/47225/ 50961 >. Acesso em: 07 Set. 2014.

MOURÃO, M. A. A.. Caracterização hidrogeologia do aquífero Cauê, Quadrilátero Ferrífero, MG [manuscrito]. 2007. 297 f. Tese (doutorado) - Escola de Engenharia, Universidade Federal de Minas Gerais, Belo Horizonte, 2007.

MUNSELL SOIL COLOR CHARTS. U.S. Dept. Agriculture handbook 18 - soil survey manual. $X$ rite (editor) 2000.

OLIVEIRA, N. V.; ENDO, I.; OLIVEIRA, L. G. S.. Geometria do Sinclinal Gandarela Baseada na Deconvolução Euler 2D e 3D - Quadrilátero Ferrífero - MG. 2005. Revista Brasileira de Geofísica. Disponível em:<

http://www.scielo.br/pdf/rbg/v23n3/a02v23n3>. Acesso em: 17 out. 2014. ISSN 0102-261X.

PORTILHO, S.; MIRANDA, B. N.. Relações Entre A Erosão Laminar A Taxa De Infiltração De Água No Solo Em Diferentes Pontos Da Encosta, Microbacia Do Ribeirão Gomes De Melo, Sub-Bacia Do Rio Piracicaba, Município De Rio Piracicaba - MG, 2008.

PORTILHO, S.; GREGÓRIO, S. I. F. F. Estudo Da Técnica De Terraceamento Utilizada $\mathrm{Na}$ Recuperação De Áreas Degradadas Na Sub- Bacia Ribeirão Candidópolis, Itabira -MG, 2011.

PROJETO MANUELZÃO. Serra do Gandarela. 2010. Disponível em:

<http://www.manuelzao.ufmg.br/serradagandarela/>. Acesso em: 19 set. 2015.

SCHAEFER, C.E.G.R. et al.. Solos desenvolvidos sobre canga ferruginosa no Quadrilátero Ferrífero, Minas Gerais, 2008. In: Simpósio Afloramentos Ferruginosos no Quadrilátero Ferrífero:

Biodiversidade, Conservação e Perspectivas de Sustentabilidade. Belo Horizonte, 109-121. CD. apud CARMO, Flávio Fonseca do. Importância Ambiental e Estado de Conservação dos Ecossistemas de Cangas no Quadrilátero Ferrífero e Proposta de Áreas-Alvo para a Investigação e Proteção da Biodiversidade em Minas Gerais. 2010. $90 f$. Dissertação (Mestrado em Ecologia, Conservação e Manejo da Vida Silvestre) - Universidade Federal de Minas Gerais, Belo Horizonte, 2010. Disponível em:< http://www.icb.ufmg.br/pgecologia/dissertacoes/D240_ flavio_foneca_do_carmo.pdf >. Acesso em: 07 set.

2014.
SALGADO, A. A. R.. Estudo da evolução do relevo do Quadrilátero Ferrífero através da quantificação dos processos erosivos e denudacionais. 2006. Tese (Doutorado em Geoquímica Ambiental) - Escola de Minas, Departamento de Geologia, Programa de pós-graduação em Geologia Ambiental e Conservação de Recursos Naturais, Universidade Federal de Ouro Preto, Ouro Preto, 2006. Disponível em:

<http://www.repositorio.ufop.br/handle/123456789/325 6>. Acesso em: 30 out. 2015.

SANTOS, R. D. et al.. Manual de descrição e coleta de solo no campo. 2013. 6ª edição. Revisada e Ampliada. Viçosa. Sociedade Brasileira de Ciência do solo, 2013.

SANTOS, C. T.; VIDAL, D. M.. Sistemas filtrantes para estabilização de colúvios - Importância da estrutura do solo. 2003. Instituto Tecnológico de Aeronáutica. São José dos Campos - SP. Disponível em:

<http://www.bibl.ita.br/ixencita/artigos/Infra01.pdf>. Acesso em: 15 de Nov. de 2015.

ShINZATO, E; CARVAlHO FILHO, A. Projeto APA Sul RMBH: estudos do meio físico, pedologia. Belo Horizonte: CPRM/EMBRAPA/SEMAD/CEMIG, 41 p., 2005 apud MARENT, B. R.. Unidades De Paisagem Nas Bacias Hidrográficas Do Alto Ribeirão Da Prata E Ribeirão Preto Na Serra Do Gandarela, Quadrilátero Ferrífero - MG. 2013. 19 Folhas. Monografia - Centro Universitário de Belo Horizonte, Centro Universitário de Belo Horizonte, Belo Horizonte, 2013.

SILVA, J. R.; SALGADO, A. R.. Mapeamento das unidades de relevo da região da Serra do Gandarela - Quadrilátero Ferrífero/MG. 2009. Belo Horizonte. Artigos Científicos. Book Geografias v5 n2.indb 107. Disponível em:< http://www.igc.ufmg.br/portaldeperiodicos/index.php/ge ografias/article/download/491/363>. Acesso em: 09 de Abr. de 2017. 